MMR safety, and nearly a quarter $(22.7 \%, \mathrm{n}=60)$ were rated as "mixed". In 2000, despite growing public concerns and widespread media coverage, fewer than 20 comment pieces were published. From 2001-2003 the tone of many articles was negative, mixed or neutral, thus conveying ambiguous or negative messages about MMR safety to health professionals, though from 2004 the tone changed and most comment pieces were broadly positive. Overall less than a quarter of comment pieces ( $n=196,22.7 \%$ ) included reference to current recommendations or other guidance on MMR. This was particularly notable in the period from 1998-2001, following publication of the Wakefield paper in 1998.

Conclusion: During the MMR controversy journals and magazines aimed at health professionals may have added to uncertainty among practitioners by failing to reinforce current practice with evidence-based recommendations about MMR safety. The findings raise questions about how far journals and magazines should go in supporting current public health policy, and how far they should leave readers to make up their own minds.

\section{ASSOCIATION BETWEEN VOLUME AND OUTCOME FOR ADULT GENERAL CRITICAL CARE UNITS IN ENGLAND, WALES AND NORTHERN IRELAND}

C Welch, D Harrison, K Rowan. Intensive Care National Audit and Research Centre, London, UK

\section{doi:10.1136/jech.2009.096727y}

Introduction: Volume: outcome associations are well established in the surgical literature. In 1995, ICNARC first investigated whether a potential volume: outcome association existed in critical care but found no evidence. Since then, other international studies have investigated this both for all admissions and for admissions receiving mechanical ventilation. Most of these studies have found an association. This study re-investigates the volume: outcome association for admissions to critical care units in the UK, now using a much larger, more representative sample of critical care units.

Methods: Data were extracted from the Case Mix Programme Database (CMPD) for 672626 admissions to 199 adult, general critical care units from 1995 to 2008. The critical care units were split into quartiles by volume of admissions over a two-year period from 1/1/06 to 31/12/07 (units with less than two years' data were scaled up). Multilevel logistic regression was performed to investigate the association between ultimate acute hospital mortality and quartile of volume, adjusted for case mix and hospital type. This analysis was then repeated solely for admissions receiving mechanical ventilation.

Results: Between 1/1/06 and 31/12/07 there were 154905 admissions to 172 units. For all admissions and for mechanically ventilated admissions, crude ultimate acute hospital mortality decreased as volume increased across each quartile. The decrease in mortality was explained by case mix with lower severity of illness of admissions in units with higher volume. The results of a multilevel logistic regression analysis for all admissions found no evidence of an association between ultimate acute hospital mortality and quartile of volume, adjusted for case mix and hospital type $(p=0.126)$. However, odds ratios for ultimate acute hospital mortality for mechanically ventilated admissions did decrease as volume increased across each quartile, but the association was not statistically significant $(p=0.182)$.

Conclusion: For all admissions and for mechanically ventilated admissions to adult, general critical care units in England, Wales and Northern Ireland, this study found no evidence of an association between ultimate acute hospital mortality and the volume of admissions to the critical care unit

\section{INDEPENDENT SECTOR TREATMENT CENTRES: LEARNING FROM A SCOTTISH CASE STUDY}

AM Pollock, G Kirkwood. Centre for International Public Health Policy, University of Edinburgh, Edinburgh, UK

doi:10.1136/jech.2009.096727z

Objective: The English Independent Sector Treatment Centre (ISTC) programme uses the private health care industry to provide elective surgery and other clinical services at a projected total cost of $£ 5$ billion. To date the government has contracted for $£ 2.7$ billion worth of services but the programme remains unevaluated because of a lack of published contract data and poor quality data returns. Scotland has a three year pilot ISTC, the Scottish Regional Treatment Centre (SRTC) worth $£ 18.7$ million the contract for which is now in the public domain. This study aims to conduct an independent evaluation of the performance of the SRTC during the first year of operation.

Design: A retrospective analysis of the SRTC comparing activity as reported by hospital episode statistics returned to ISD Scotland with volume and cost data in the SRTC contract and a 10-month audit carried out by management consultants Price Waterhouse Coopers (PWC).

Setting and Participants: All day case and inpatient activity at the SRTC from 1 December 2006 to 31 December 2007.

Main Outcome Measure: Activity and cost.

Results: The annual contract was based on payment for referrals to the SRTC, not actual treatments and specifies a $90 \%$ minimum payment on referral value. The contract was awarded on the basis of 2624 referrals a year at a total value of $£ 5667464$. According to ISD data, the SRTC performed 831 procedures (32\% of annual contract volume) in the first 13 months worth $£ 1035603$ (18\% of annual contract value). PWC's figures report 2200 referrals (84\%) to the SRTC at a cost of 22642000 (47\%) in the first 10 months. Conclusions: The SRTC contract is based on payments for referrals and not actual treatment, as were the wave one English ISTC contracts. This represents a major departure from the normal standards of reporting and commissioning. Also the non-default event exemption clause in the contract means referring health boards retain the risk for many situations where treatment is not completed. This appears to be resulting in payment for non activity which may mean as much as three quarters of the work paid for as referrals haven't been completed as treatments. Neither PWC's analysis nor claim of value for money can be substantiated. We recommend a moratorium on all ISTC contracts until the contracts have been published and properly evaluated with respect to work paid for and actual work carried out and quality of care.

\section{Measurement and recognition of adiposity}

\section{ACCURACY OF HEIGHT AND WEIGHT DATA FROM CHILD HEALTH RECORDS}

${ }^{1.2 \mathrm{LD}}$ Howe, ${ }^{1} \mathrm{~K}$ Tilling, ${ }^{1,2} \mathrm{DA}$ Lawlor. ${ }^{1}$ Department of Social Medicine, University of Bristol, Bristol, UK; ${ }^{2}$ Medical Research Council Centre for Causal Analyses in Translational Epidemiology, University of Bristol, Bristol, UK

doi:10.1136/jech.2009.096735a

Background: Height and weight measurements routinely collected for child health records are potentially useful for both clinical practice and research, but there is limited knowledge of their accuracy.

Data and Methods: Height/length and weight measurements from clinics of the Avon Longitudinal Study of Parents and Children (ALSPAC) were used as a gold standard against which to assess the accuracy of routinely collected measurements recorded in the Personal 